\title{
Auge y caída de la Organización Sindical Española ${ }^{1}$
}

\author{
Álvaro Soto CARMOna
}

A principios de los años cincuenta, la Dictadura entró en una fase de consolidación, favorecida por el crecimiento económico y las transformaciones sociales que se venían produciendo. La década de los cincuenta experimentó un significativo crecimiento del Producto Interior Bruto (a una tasa de aumento anual acumulativo del $5,3 \%$ en los años 1950-58), que pone en cuestión la generalizada afirmación de que sólo puede hablarse de crecimiento económico en España a partir de 1959. De hecho, durante 1950 y 1951, la tasa de crecimiento de la economía española aumentó a ritmos superiores a los establecidos por los Planes de Desarrollo de los años sesenta.

A partir de la citada década se producen cambios demográficos profundos, unidos a un intenso proceso de desagrarización y urbanización ${ }^{2}$. Se produce así mismo el aumento de los niveles de instrucción y la modificación del sistema educativo, transformaciones en la estructura ocupacional, el incremento de la población asalariada, y la mejora del nivel de vida ${ }^{3}$.

Los cambios en la economía y en la estructura social, junto a la mejora del nivel de vida, fueron acompañados por el aumento de las protestas sociales y, en el campo político, por la incompatibilidad cada vez más profunda entre la modernización de la sociedad y el "continuismo" político.

\footnotetext{
Este artículo forma parte de la ponencia presentada en el Congreso Internacional, que sobre El Régimen de Franco (1936-1975), se celebró en Madrid (Universidad Nacional de Educación a Distancia) entre el 11 y el 14 de mayo de 1993.

$2 \quad$ "... el auge de las ciudades españolas en la última década es tan espectacular que apenas se puede encontrar otro ejemplo similar en toda Europa en los últimos tiempos", DE MIGUEL, A. y J. SALCEDO: Dinámica del desarrollo industrial de las regiones españolas, Madrid, Tecnos, 1972, pág. 67.

3 Entre 1950 y 1975 el nivel de vida se duplicó, en SERVICIO SINDICAL ESTADÍSTICA: Aproximación a un indice de evolución del nivel de vida para el periodo 1950-1975. Madrid, Ediciones y Publicaciones Populares, 1977, pág. 144.
} 
La politización por parte de los gobernantes españoles, así como de los que impulsaban el conflicto hizo que toda protesta tuviera un carácter de confrontación política, y que ésta estuviese cada vez más presente en los comportamientos ciudadanos. No toda las personas que se movilizaban lo hacian contra el Régimen; pero sí se politizaba toda movilización, dejando patentes las fisuras de unas estructuras políticas caducas. Los conflictos habidos durante estos años tuvieron pues naturaleza política ${ }^{4}$.

La toma de conciencia de la nueva situación por parte del personal político afín a la Dictadura dio ocasión a una lucha sorda y continua. Esta lucha se manifestó en los años cincuenta entre las "familias políticas" que tradicionalmente habían apoyado al dictador, las cuales fueron variando su composición y objetivos. Todo ello se concretó en la década siguiente cuando el conflicto intra-régimen se centró en torno a la forma -persona-que sustituiria al dictador, junto al papel y funciones del Movimiento y a los posibles canales de participación política; dicho conflicto tuvo unos vencederos tras la «crisis de 1969». Por último, en los años setenta, el enfrentamiento entre el personal político del régimen tuvo como finalidad tomar posiciones ante la cada vez más cercana muerte de Franco ${ }^{5}$.

El régimen tuvo una composición plural en sus apoyos, las citadas "familias políticas", todas ellas sometidas al arbitraje de Franco. Pero se ha incurrido en un error a la hora de extender su funcionamiento a todos los años de la Dictadura, ya que las mismas tendieron a diluirse con el paso del tiempo. Hasta la crisis política de febrero de 1956 se aprecian tensiones entre las familias políticas, siendo en estos años cuando se produce el último conflicto de dicha naturaleza. Este viene dado, entre otros motivos, por la presentación por parte de José Luis de Arrese ${ }^{6}$ de una serie de proyectos de Leyes Fundamentales, que tenían por objetivo revitalizar y potenciar

${ }^{4}$ Dicha tesis se encuentra expuesta, entre otros, en: $1^{9}$ ) Ministerio de Trabajo: “Criterios ante una posible situación conflictiva", s.t. (finales de 1971), Fondo de Maria Luisa Suárez, Archivo Histórico de Comisiones Obreras - Fundación Primero de Mayo (en adelante AHCO-FPM), carpeta, 63-7, pág. 10; $2^{\circ}$ ) Álvarez JunCo, J.: «Movimientos sociales en España: del modelo tradicional a la modernidad postfranquista", en Laraña, E. y J. Gustield (eds.): Los nuevos movimientos sociales, Madrid, CIS, 1994, pág. 430; $3^{\circ}$ ) Soro, A.: «Long Cycle of Social Conflict in Spain (18681986)", Review, Xvı, 2, spring 1993, págs. 173-197.

5 Dos posturas aparecen nitidas, por un lado aquellos que apoyándose en FERNÁNDEZ CARVAJAL tratan de "autentiticar" las Leyes Fundamentales; por otro, los trabajos de HERRERO DE MIÑÓN, DE ESTEBAN y ARIAS SALGADO, que tratan de interpretar en sentido liberalizador las Leyes Fundamentales.

- ARESE, J.L. DE: Una etapa constituyente, Barcelona, Planeta, 1982. Los proyectos se encuentran recogidos en los arejos 6, 7 y 8, en LoPEz Rodo, L.: Memorias, I, Barcelona, Plaza \& Janes, 1990, págs. 624-640. 
el papel del partido único, en especial su Consejo Nacional. Ello implicaba, aunque no de forma abierta, el cuestionamiento de la Monarquía instaurada en 1947 por la Ley de Sucesión a la Jefatura del Estado.

Los referidos proyectos fueron especialmente contestados por Carrero Blanco, por aquel entonces ministro subsecretario, que como era habitual en él tomó postura mediante una nota escrita ${ }^{7}$ en la que situaba a la Monarquía en primer lugar, aunque realizando una cesión terminológica a Falange, denominándola "social», e indicando a su vez que la Monarquía se inspiraría en «la Ley de Dios según las doctrinas de la Santa Iglesia Católica Apostólica Romana». La propuesta de Carrero Blanco, fiel a su pensamiento, suponía ante todo la definición de una monarquia tradicional.

En una línea crítica con la oportunidad de los proyectos se manifestó, entre otros, Esteban Bilbao, presidente de las Cortes, que pensaba que los mismos "en lugar de unirnos nos dividen" ${ }^{8}$. Para los católicos que colaboraban con el régimen, los proyectos entraban:

"(...) en discordancia con las leyes principales fundamentales hasta ahora dictadas y que a nuestro parecer salvaguardan mejor los derechos de las personas humanas que la Iglesia propugna. (...)

Los proyectos de Leyes Fundamentales, lejos de favorecer la unión nacional con la base del espíritu de 18 de julio, producirían una peligrosísima división entre los ciudadanos españoles, siendo así que la Iglesia procura siempre la unidad y la concordia.

Para asegurar la continuación del espíritu del Movimiento Nacional es necesario ni recaer en el liberalismo de una democracia inorgánica, ni pretender una dictadura de partido único, sino promover una actuación y verdadera representación orgánica ${ }^{9} \%$.

Dicho debate, en el que se aprecia con claridad los posicionamientos de las "familias políticas", terminó con la derrota de los falangistas cuando Franco entregó a Arrese una «lista de quince protestas contra las disposiciones en tramitación que a éste le parecieron otras tantas sentencias de muerte" ${ }^{10}$. En el fondo se trataba de obtener ventajas partidistas en el proceso de institucionalización del régimen, que impidiesen a aquellos que no se alinearan con dichos principios acceder al poder.

Tusell, J.: Carrero. La eminencia gris del régimen de Franco, Madrid, Temas de Hoy, 1993, págs. 224 y ssg.

8 LóPEz Rodó, L.: Memorias, op. cit., anejo 9, pág. 650.

9 Citado por Tussel, J.: Franco y los católicos, Madrid, Alianza Universidad, 1984, pág. 422.

10 Tussel, J.: Carrero..., op. cit., pág. 226. 
El cambio de gobierno producido en febrero de 1957 fue uno de los más decisivos del régimen, no sólo por la magnitud del mismo (de dieciocho ministros cambiaron doce), sino por la derrota de Falange y de la Asociación Católica Nacional Propagandista, implicando un cambio de rumbo. Se pasó de una etapa de supervivencia y consolidación, a otra de institucionalización, en la cual el papel de Carrero Blanco será cada vez más visible, convirtiéndose en el centro de las iniciativas políticas. Al mismo tiempo se asistió al ascenso de personajes denominados tecnócratas (Navarro Rubio, Ullastre...) que iban a impulsar, junto a otros como López Rodó, un giro en la política económica, en la administración del Estado, en el ámbito militar y en el de las libertades públicas, aunque en estos dos últimos casos los avances fueron muy modestos.

Estos cambios, y los habidos en los años sucesivos hasta el asesinato del presidente de Gobierno en diciembre de 1973, conllevaron un creciente posicionamiento de numerosos políticos (Carrero, Muñoz Grandes, Solís, Fraga, López Rodó...) y supusieron no ya un conflicto entre familias, sino entre normas, cuya finalidad era la "institucionalización" y "desarrollo político" del régimen, desarrollo de cara al futuro una vez desaparecido Franco. Sólo entendiendo este cambio, se puede comprender el que una parte de los apoyos de la Dictadura (los reformistas) se conviertan en los protagonistas del posterior proceso de transición.

El Sindicato se convirtió en el baluarte de aquellos que no estaban dispuestos a que Juan Carlos fuese nombrado "sucesor" 11. Para ello propiciaron un reforzamiento del Movimiento que, tras la muerte de Franco, les situó en un continuismo militante, en una línea de "perfeccionamiento" que entendía necesarias ciertas reformas para lograr la denominada "democracia a la española» ${ }^{12}$, lo cual significaba en la práctica una limitación de la misma.

Desde la llegada de Solís a la Delegación Nacional de Sindicatos (1952) ésta adquiere una importancia singular, mayor de la que se le ha venido dando, e incluso mayor que en los años anteriores. Pero dicho poder se ve totalmente trastocado tras la salida de Solís de la Secretaría

11 Durante una entrevista mantenida por Juan Vilá Reyes con Solis, poco antes de que estalle el escándalo MATESA, éste último le dijo: "Mira, estamos en la recta final y pronto va a haber cambios importantes. Esto va a acabar mal. Se esta apretando para consolidar a Juan Carlos, cuando España está harta de Borbones, que siempre ha terminado mal. Como si no hubiera otros posibles sucesores de Franco"., en VILA REYES, J.: El atropello MATESA, Barcelona, Plaza \& Janes /Cambio 16, 1992, pág. 68.

12 "Discurso de Calos Arias Navarro", CoRtes Españolas: Diario de Sesiones del Pleno, 23, 28 de enero de 1976, pág. 6. 
General del Movimiento (1969), a partir de la cual se entra en una fase de pasividad. Durante dichos años (1952-69) el Sindicato pasa de la ortodoxía falangista a un pragmatismo con fuerte dosis de "desideologización». Junto a ello el Sindicato se va a ver sometido a la presión desde las bases por la acertada estrategia de comunistas y católicos de utilizarlo para forzar la democratización no sólo de las relaciones laborales, sino también de la sociedad en su conjunto. Por otra parte, la conflictiva situación provoca una actitud de los gobernantes tendente a la marginación del Sindicato tras la aprobación de la Ley Sindical en $1971^{13}$.

Desde 1959, aunque la fecha sea un dato orientativo, la naturaleza del conflicto intra-régimen no sólo tiene unos nuevos protagonistas, sino sobre todo unos renovados objetivos. Sucede igual con la oposición extra-régimen, que sufre una trascendental mutación que la hace más efectiva, más posibilista y visible en la sociedad española. Debido a todo ello los medios a utilizar y la repercusión de las respuestas hacen que el conflicto social no sólo incremente su magnitud, sino que intensifique su naturaleza política. Ya no se trata de una vuelta al pasado, sino de una salida de futuro. En todo caso el protagonismo y la influencia de cada uno de los grupos de oposición no fue similar; aquellos que detentaban parte del poder o se encontraban en los entresijos del mismo tenian más fuerza, por lo que su papel, sin desechar a los que estaban fuera de dichos ámbitos, fue decisivo.

\section{UN CONFLICTO INTRA-RÉGIMEN: EL DEBATE DE LA LEY SINDICAL}

El modelo sindical impuesto por la Dictadura tuvo los siguientes rasgos característicos ${ }^{14}$ :

$\left.1^{\circ}\right)$ La sindicación se declaraba obligatoria, aunque no formalmente, de hecho sobre dicho tema hubo fuertes discrepancias. En términos generales se puede afirmar "que el corporativismo católico y el tradicionalista propugnaban la libertad individual de sindicación en tanto en cuanto el sindicato se debía integrar necesariamente en la corporación obligatoria; por el contrario, el sector falangista abogaba por la obligatoriedad» ${ }^{15}$.

\footnotetext{
13 Véase Iglesias Seglas, C.: Comentarios a la Ley Sindical, Madíd, Cabal, 1971.

14 Borrajo Dacruz, E.: Derecho comparado del trabajo, Madrid, Centro Iberoamericano de Relaciones Industriales, 1986, págs. 46 y 47

is ApaAicio, M.A.: El sindicalismo vertical y la formación del Estado franquista, Barcelona, EUNIBAR, 1979, pág. 134.
} 
Aunque esto último también es matizable ya que Gerardo Salvador Merino no se mostraba a favor de la misma ${ }^{16}$.

Dicho debate fue en realidad estéril, ya que se impuso la obligatoriedad en su acepción más radical: la sindicación automática por el hecho de poseer la condición de empresario o trabajador. Y ello lo debemos de entender como el desarrollo lógico de uno de los principios establecidos en el Fuero del Trabajo $(\mathrm{FT})$ : el de totalidad. Este principio tiene una doble acepción: al relacionarse con el de unidad, tratando por un lado de encuadrar a todos los empresarios y trabajadores en el ámbito de representación del sindicato; y al extender la organización sindical a todos los sectores y ramas de la economía.

El principio de totalidad no alcanzó plena efectividad, como se pone de manifiesto en las profesiones libres que mantuvieron su organización (Colegios Profesionales ${ }^{17}$ ), o los funcionarios públicos ${ }^{18}$ que quedaron excluidos de cualquier forma de sindicación. Por ello hay que distinguir entre lo legal y lo real. El estudio únicamentente del desarrollo legislativo proyecta una imagen distorsionada de lo que realmente sucedió.

$\left.2^{\circ}\right)$ Se proclamaba la unidad en un mismo sindicato de empresarios y trabajadores. En el Fuero del Trabajo se rechazaba el pluralismo sindical, apostando por un modelo futuro donde se «determinará la forma de incorporar a la nueva organización a las actuales asociaciones económicas y profesionales" ${ }^{19}$, como así se hizo en la Ley de Unidad Sindical ${ }^{20}$, que en su artículo $1^{\circ}$ decia:

"La organización sindical de Falange Española Tradicionalista y de las JONS es la única reconocida con personalidad suficiente por el Estado, quien no admitirá la existencia de ninguna otra con fines análogos o similares,..." (El subrayado es nuestro).

La misma ley obligaba a las asociaciones que defendian intereses económicos o de clases, tanto patronales, obreras, o gremiales, a incorporarse "a la organización sindical del Movimiento" ${ }^{21}$. Pero al igual que en el caso anterior, al amparo de esta misma Ley subsistieron ciertos organismos de representación económica y profesional. Asi sucedió por ejemplo con las

\footnotetext{
16 "Discurso de Gerardo Salvador Merino, pronunciado el 20 de junio de 1941 en la clausura del II Congreso Sindical", Boletin Sindical de la CNS, 12, Barcelona, julio-agosto-septiembre 1941.

17 "Las protesiones liberales y técnicas se organizarán de modo similar, conforme determinan las Leyes", Declaración xII, punto 2, final del Fuero del Trabajo, y también Circular de 28 de julio de 1941.

18 Orden de 24 de mayo de 1942 y su aclaración en la de 11 de agosto de 1953.

19 Fuero del Trabajo, Declaración XIII, punto 9.

20 Ley de Unidad Sindical de 26 de enero de 1940 (BOE del 31).

21 Artículo $2^{\circ}$.
} 
Cámaras Oficiales de Comercio, Industria y Navegación ${ }^{22}$, las Cámaras Oficiales de Sindicación Agraria (COSA), además de algunos grupos profesionales que contaron con una doble representación (auxiliares sanitarios, representantes de comercio,...). Esta situación tuvo su origen en parte en la diferente postura mantenida sobre dicho tema por la Iglesia.

Los intentos de llegar a la unidad continuaron con Solís que se planteaba como uno de sus fines políticos «la absorción por la Organización Sindical de las Cámaras de Comercio, Industria y Navegación" ${ }^{23}$, objetivo que no consiguió.

El principio de unidad se manifestó más claramente en la concepción que el nacionalsindicalismo tenía sobre la posición del empresario y del trabajador, agrupando a ambos en una condición común: la de "productores". Con ello se rechazaba tanto el liberalismo económico como el socialismo. La respuesta estaba en recuperar la armonía entre los "productores» a través del Sindicato Vertical. Éste al ser una "unidad natural de convivencia" permitía la participación conjunta de patronos y obreros, a la vez que "superaba" la lucha de clases.

Pero, pese a la concepción doctrinal, la unidad de empresarios y trabajadores no fue lograda, tal y como se puso de manifiesto en la Ley de la Organización Sindical ${ }^{24}$, la cual tuvo que aceptar realidades distintas entre los trabajadores ("secciones sociales") y los empresarios ("secciones económicas»). Profundizándose aún más la distinción a raíz de la ley de 1958 sobre convenios colectivos sindicales, que implicaba el reconocimiento de un conflicto de intereses entre ambas partes. Es decir, ni la unidad ni la supresión de la «lucha de clases» pudo establecerse, pese a la reiteración de ello en la retórica oficial ${ }^{25}$.

$\left.3^{\circ}\right)$ El Sindicato se constituía como una entidad de derecho público con una personalidad jurídico-pública, aunque dicha atribución se reservó a los sindicatos en sentido estricto, siendo más tardío en el caso de la Delegación Nacional de Sindicatos ${ }^{26}$. Los demás entes sindicales funcionaban con sus propias normas ${ }^{27}$.

\footnotetext{
22 Martinez Alier, J.: “Notas sobre el franquismc", Papers, 8, 1978, pág. 29.

LÓPEZ Rodó, L.: Memorias, op. cit., pág. 276.

Ley de 6 de diciembre de 1940 (BOE del 7).

25 ARRESE, J.L. DE: La Revolución Social del Nacional-Sindicalismo, Madrid, Editora Nacional, 1950, págs. 35-54.

26 Decreto de 28 de junio de 1965.

27 Borrajo Dacruz, E.: Introducción al Derecho Español del Trabajo, Madrid, Tecnos, 1978, pág. 238.
} 


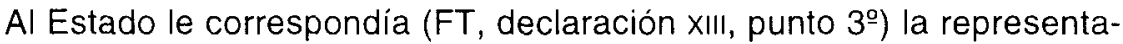
ción y desarrollo de los intereses de la totalidad de la comunidad. El Fuero del Trabajo dejaba clara la dependencia de la Organización Sindical al afirmar que "El Estado, por sí o a través de sus sindicatos..." ${ }^{28}$; igualmente se establece en la Declaración XIII de dicho texto. Todo el desarrollo normativo posterior incide en esta cuestión, por lo que no pueden existir dudas sobre la citada dependencia, que es consecuencia lógica del principio de jerarquía: los sindicatos locales quedaban subordinados a los provinciales, estos al nacional de su rama y a todos los órganos de dirección de la OSE, y todo ello subordinado a la dirección del Estado. En suma, la dirección política del Gobierno, más que la del Movimiento, era quien establecía la política a seguir por el Sindicato.

$\left.4^{\circ}\right)$ El Sindicato no tenía capacidad para realizar una presión a través de la huelga, ya que ésta estaba prohibida.

En suma, nos encontramos ante un sindicalismo de sumisión que "se caracteriza por supeditar -o confundir- los intereses de los trabajadores a los intereses del Estado, siendo precisamente la configuración del Estado la que marca la del sindicato" ${ }^{29}$.

La gestación institucional del Sindicato fue muy lenta y se prolongó al menos hasta 1957, existiendo durante los años cuarenta más sobre el papel que en la realidad. Aunque su desarrollo legislativo fue muy temprano ${ }^{30}$, su expansión y el cumplimiento de las funciones que tenía asignadas (política, asistencial, propagandística, jurídica, económica y representativa) se hicieron esperar, actuando en estos primeros años más como un elemento favorecedor de la represión y de la legitimación del nuevo régimen ${ }^{31}$.

Hasta principios de los años cincuenta el Sindicato se había movido dentro de una lógica interna con un discurso «nacionalsindicalista»; como se puso de manifiesto en el I y II Congreso Nacional de Trabajadores en

${ }^{28}$ FT, Declaración XI, punto 5․

29 SagardoY, J.A.: Relaciones de trabajo y estructuras políticas, Madrid, Instituto de Estudios Laborales y de la Seguridad Social, 1984, pág. 51.

3o Vease Aparicio, M.A.: El Sindicato Vertical..., op. cit. Para un estudio de la Organización Sindical Española, desde dentro es imprescindible la consulta de IGLEsia SELGAS, C.: LOS Sindicatos en España, Madrid, Ediciones del Movimiento, 1966.

31 «El Sindicato vertical (...) es un instrumento a través del cual se llevará a cabo la política social del nuevo régimen el que impondrá la disciplina entre los elementos que participen en la producción, el que sacará las primeras y las últimas consecuencias de la Revolución Nacional en el orden social», en DaviLA YAGÜE, M.: El Sindicato Vertical, Salamanca, M. Quero y Simón, Editor, 1938 o 1939, pág. 19. 
1946 y 1951 respectivamente, donde se seguía manteniendo la retórica «revolucionaria».

En 1952 José Solís se hizo cargo del Sindicato con el objetivo de:

«... excluir la demagogia social antigua, concertar pacíficamente a obreros y empresarios, democratizar por dentro al propio sindicalismo sin perder las ataduras con su propio mando, promover representantes expertos para las tareas legisladoras de Cortes, permanecer incontaminados de la política de enfrentamientos y contribuir a las grandes reformas económicas, sociales y tecnológicas del país..." ${ }^{32}$.

Este cambio de orientación se vio reforzado por la ascensión política de Solis, que en la remodelación gubernamental que se produjo el 25 de febrero de 1957 fue nombrado ministro secretario general del Movimiento, cargo que mantuvo hasta el mes de octubre de 1969. En tan largo período de tiempo dio al Sindicato una nueva orientación política, como se vio en el / Congreso Sindical Nacional en 1961 en el cual se definieron "las líneas de un aggiornamento caracterizado por la consigna de lograr la colaboración mayoritaria de los trabajadores, (para lo cual) se iniciará una interesada tendencia de apertura" ${ }^{33}$. El cambio se presentó como favorecedor de la participación obrera ${ }^{34}$ y vino acompañado de un incremento del poder del Sindicato, que se hizo más activo en el campo político, económico y social.

Durante este Primer Congreso como ya hemos dicho se impulsó el papel político del Sindicato. A tal fin se decidió no limitar su papel a la defensa de los intereses de los grupos profesionales, sino extender su acción para conseguir "una nueva ordenación de la sociedad" (proclamación 6). Era necesario mantener "no sólo una personalidad distinta e independiente del Estado, sino una plena autonomia funcional» (proclamación 9º), que le llevase incluso a posicionarse en contra de los criterios gubernamentales. Para poder realizar esta función el «pueblo» debía participar en la acción política del Sindicato a través de sus representantes, los cuales debian de tener la palabra en aquello que afectase a:

32 Romero, E.: Tragicomedia de España (Unas Memorias sin contemplaciones), Barcelona, Planeta, 1985, págs. 92 y 93.

33 SANCHEZ, R. Y M" E. NiCOLAS: "Sindicalismo vertical franquista: la institucionalización de una antinomia", en D. Ruíz (dir.): Historia de Comisiones Obreras (1958-1988), Madrid, Siglo XXI, 1993, pág. 3.

${ }_{34}$ Solis Ruiz, J.: El Sindicalismo Nacional en la vanguardia por una España nueva, (Intervención en el acto de clausura del I Congreso Sindical), Madrid, SIPS, 1961. 
“a) Las tareas legislativas.

b) A las demás funciones de interés general.

c) Al perfeccionamiento de los fines de la comunidad nacional.

d) $\mathrm{Al}$ ejercicio de los derechos y deberes del hombre en orden al bien común; y

e) A participar en las tareas del Estado." (Proclamación 14..$^{\circ}$ )

Así se completaba el intento más desarrollado y serio de inmiscuirse en las actividades de gobierno, manteniendo la independencia. Ello suponía la creación del mayor grupo de presión organizado de la política española. Esta línea fue mantenida durante toda la década, tanto en los textos programáticos (II Congreso Sindical -1962- y III Congreso Sindical -1964- ${ }^{35}$ y IV Congreso Sindical -1968-), como en la actitud de sus dirigentes.

Desde el punto de vista político, en los años sesenta se entabló una batalla entre dos sectores presentes en el Gobierno, los encabezados respectivamente por López Rodó y el propio Solís, que si bien coincidían en la fidelidad al Jefe del Estado y competían por sus "favores", al igual que coincidian en la necesidad del "Alzamiento", discrepaban en la forma de llevar a cabo la institucionalización del régimen y en el poder que debian de tener las instituciones por él creadas, así como en las pautas a seguir en la política económica y como derivación de ello en la social.

Dichas discrepancias eran visibles no sólo en el interior del Consejo de Ministros, sino en las declaraciones y mensajes que cada uno de dichos sectores hacían llegar a la opinión pública a través de los medios de comunicación controlados por ellos mismos. Así, López Rodó el 3 de mayo de 1966 comunicó a Franco la existencia de una campaña de prensa "reincidente" desde la OSE en la que se atacaba a la política económica, lo cual demostraba "la división en el seno del Gobierno y la indisciplina en la Organización Sindical» ${ }^{36}$. En otra reunión, también con Franco, denunció la publicación por el Sindicato de "un alegato de 300 páginas contra la política económica del gobierno". En la misma línea se

35 Durante el II Congreso fue aprobada una ponencia que insistía en el hecho de que el Sindicato fuese un poder del Estado: "En esta situación nueva el Siridicato es invitado por el propio Estado a superar el marco puramente profesional, a elevarse a la preocupación de la economia nacional en su conjunto y por tanto a abordar problemas netamente políticos (...).

Así se produce el último punto de inflexión: las posiciones de independencia reciproca del Sindicato y Estado viene a ser superadas en una situación de interdependencia. El Sindicato es menos libre frente al Estado; el Estado es menos libre frente al Sindicato".

36 Hasta la siguiente cita todas las frases entrecomilladas se hallan en LóPzz RODO, L.: Memorias. Años decisivos. II, Barcelona, Plaza \& Janes, 1991, pág. 33, 46, 93, 525, págs. 525 y 526, y pág. 526. 
produjo un enfrentamiento verbal entre Solís y el propio López Rodó en el Consejo de Ministros del 28 de octubre de 1966, en el cual el segundo denunció la publicación de un artículo en el diario Arriba en el "que se atacaba duramente a la Comisaría del Plan de Desarrollo». Para Solís los Sindicatos debían jugar un papel decisivo en la elaboración de la política económica:

"Los artífices o ejecutores del desarrollo elaborado por nuestro Gobierno no pueden ser otros que los trabajadores y los empresarios, y todos ellos, por disposición de nuestras leyes, están en los Sindicatos. No podrá llevarse a la práctica un Plan de Desarrollo sin el mundo sindical, sin su colaboración y $\sin$ sus responsabilidades" ${ }^{37}$.

Las diferencias entre ambos no sólo se pusieron de manifiesto en la política económica, sino en relación al propio poder del Sindicato, concretándose en la oposición de López Rodó a las iniciativas de Solís y de la OSE tendentes a reforzar el poder de esta última. Dichas iniciativas según Franco podían favorecer la existencia de "un Sindicalismo omnipotente». López Rodó consideraba dicho tema "el de mayor importancia en estos momentos, porque es el que entraña mayores riesgos para el futuro del Régimen". Esta afirmación se realizó en octubre de 1969 y tenía por objetivo descabalgar del poder al grupo encabezado por Solís, para lo que se consideraba imprescindible:

«..., sustituir al Ministro Secretario General del Movimiento antes de que la Ponencia informe las enmiendas que ya se están presentando y, sobre todo, antes de que comiencen las discusiones en las Cortes de la Ley Sindical."

Las discrepancias fueron en algún momento especialmente ásperas, llegándose a criticar el propio pensamiento religioso de López Rodó, que como era público pertenecía al Opus Dei. La crisis de finales de octubre de 1969 dejó fuera de juego a Solís, que había tratado de controlar la política económica a través del Sindicato y con ello de presionar a favor de una línea política favorable a su clientela, que se nutría de sectores renovadores del Consejo Nacional del Movimiento y del propio Sindicato.

Se trató, en suma, de un conflicto intra-régimen en el que aún no se puede hablar de reformistas, pues estos no aparecerán hasta el primer

37 Solis Ruiz, J.: Actualidad de nuestro sindicalismo, (Discurso pronunciado en el Palacio de Deportes de Madrid en el acto organizado por la Junta Nacional de Elecciones Sindicales para dar posesión a los nuevos Vocales Nacionales), folleto núm. 48, Madrid, Colección Síntesis, SiPS, 1964, pag. 11 
quinquenio de la década siguiente, pero sí de inmovilistas, que tienden a agruparse en torno a la Hermandad de Excombatientes o a la recién nacida Fuerza Nueva; y de continuistas, los cuales buscan una fórmula que, respetando los principios del "18 de julio", permita un "perfeccionamiento" del régimen. Tanto Solis como López Rodó, a diferencia de los anteriores grupos, entendían, aunque desde distintas ópticas, la necesidad de variar el nivel de participación de los ciudadanos en la toma de decisiones, potenciando el papel de las instituciones, y reforzando con ello el control político de las mismas. Trataban de lograr una cierta liberalización, no democratización, que al son del aumento del nivel de vida favoreciera la ampliación del "bienestar». El sector encabezado por López Rodó deseaba conseguir una «despolitización», que permitiera la salida política desde la monarquía instaurada en la persona de Juan Carlos. El sector en el que se encuadraba Solís apostaba por una "politización excluyente", donde se reafirmasen los principios, pero a la vez se permitiera la construcción de un partido que controlase la sociedad. Dicho partido tendría su dirección política en el Movimiento-asociación y el apoyo de masas en el Sindicato.

Hasta la crisis de octubre de 1969 ambos grupos se apuntan triunfos. Así Solis consigue aumentar el peso cualitativo ${ }^{38}$ de los «representantes de los Sindicatos Nacionales", tal y como establecía la Ley Orgánica del Estado (LOE) ${ }^{39}$, al fijar el número de los mismos en ciento cincuenta. De esta "forma se acaba con la situación anómala anterior, evitando la enorme inseguridad que posiblemente sentian las jerarquias sindicales sin saber a ciencia cierta si eran o no representantes potenciales del pueblo español» ${ }^{40}$. De hecho se reforzaba así el papel de la dirección del Sindicato a la hora de designar "electivamente" - fórmula que ocultaba la designación digital- a los procuradores del tercio sindical.

Esta representación política venía a completar a la establecida en la Ley de Sucesión a la Jefatura del Estado, que dio cabida a un procurador sindical en el Consejo del Reino; a la participación de un representante sindical en la Comisión Permanente de las Cortes, tal y como recogía su reglamento; $y$, por último, a la reconocida ${ }^{41}$ en 1964 donde se establecía una participación de la OSE como tal en el Consejo Nacional del Movimiento. Como

38 Eficacla social y sindicalismo, Madrid, Ediciones del Movimiento, 1967, pág. 218.

39 Ley aprobada en las Cortes el 22 de noviembre de 1966, y plebiscitariamente por los españoles el 14 de diciembre del mismo año.

40 Bañón Martinez, R.: Poder de la burocracia y Cortes franquistas 1943-71, Madrid, Instituto Nacional de Administración Pública, 1978, pág. 96.

41 Decreto de 22 de abril de 1964. 
afirmaba Herrero Tejedor ${ }^{42}$, se producía así una triple vinculación del Sindicato con el Movimiento: institucional, doctrinal y orgánica.

También debe considerarse un éxito el activo papel que va a adquirir el Sindicato gracias a la Ley de Convenios Colectivos Sindicales. Pese a alguna limitación, como la introducida en el artículo 13 que establecia que la aprobación definitiva de lo acordado era competencia del Ministerio de Trabajo, la realidad es que se va a pasar de una etapa en la que la determinación de las condiciones de trabajo se venía realizando al margen del Sindicato, viéndose reducida su labor "a formular propuestas que no siempre merecían la conformidad" "3, a una nueva fase en donde va a jugar un activo papel en la negociación colectiva, fijando las condiciones de trabajo y participando en el establecimiento de cualquier decisión en tal sentido. Dicho papel va ser aún mayor al darse una simbiosis entre el Sindicato y el Ministerio de Trabajo, convirtiéndose así en un importante grupo de presión que apoya determinadas posiciones políticas dentro del propio Gobierno.

No se puede decir que las normas de obligado cumplimiento restasen poder al Sindicato, pues las mismas no tenian un peso cuantitativo sobresaliente, e incluso cuando se establecen antes de 1970 se dirigen en ocasiones contra el equipo económico del Gobierno, lo cual demuestra aún con mayor claridad la actitud política de dicho grupo de presión.

No obstante, pese a la mayor participación en los organismos encargados de definir la política económica, sus posturas son permanentemente desatendidas, lo que le lleva a un creciente enconamiento. En tal sentido, y no como mera anécdota, es conveniente conocer que ante el debate en Cortes de los tres Planes de Desarrollo hubo en todos los casos enmiendas impulsadas desde el Sindicato, que si bien no implicaban de manera formal un cambio sustancial en los mismos, si representaban una actitud política de enfrentamiento con las directrices marcadas desde el equipo económico del Gobierno. Por ejemplo, ante el I Plan de Desarrollo se presentó una enmienda a la totalidad, cuyo primer firmante fue Dionisio Martín Sanz (Presidente de la Sección Económica del Sindicato Nacional del Olivo). Durante las discusiones previas del // Plan, un informe elabo-

\footnotetext{
42 Herrero Tejedor, F.: «La naturaleza de la Organización Sindical Española en el Derecho positivo vigente", conferencia pronunciada en la clausura del Primer Curso de Perfeccionamiento y Especialización para Letrados de los Servicios Juridicos Sindicales, celebrada el dia 16 de julio de 1961. Publicada con el título: "La Organización Sindical en el Derecho positivo", en Cuadernos. 6. separata, Madrid, Gabinete de Estudios de los Servicios Juridicos Sindicales, 1965.

4.3 Iglesia Selgas, C.: Los Sindicatos..., op. cit., pág. 284.
} 
rado por Espinosa Poveda (Secretario General de la Organización Sindical) afirmaba "que se opondría al II Plan de Desarrollo" ${ }^{44}$. Lo mismo ocurrió al debatirse el III Plan -1972-, donde de nuevo Dionisio Martín sostuvo "que la elaboración del Plan de Desarrollo debía corresponder a la Organización Sindical» ${ }^{45}$.

Tengamos en cuenta que la actitud de los procuradores o cargos que se muestran contrarios a la política económica en un régimen de las características del franquismo, sólo se puede explicar si están avalados políticamente desde la propia cúpula del Sindicato o, como ocurre en 1972, por el enfrentamiento dentro de la misma organización tras el desplazamiento de Solís.

Como queda dicho el objetivo fundamental de la política encabezada por José Solís respecto al Sindicato era dotar al mismo de un mayor poder, concediéndole más autonomía frente al Gobierno. Para ello era necesario llevar a cabo un cambio legislativo. En dicho contexto debemos de situar el prolongado debate sobre el nuevo proyecto de Ley Sindical. En esta ocasión, no sólo nos vamos a encontrar con las posiciones diferenciadas entre Solis y Lopéz Rodó, sino también entre el primero y Romero Gorría, pues éste último quería convertir a "los sindicatos en un nuevo Instituto Nacional de Previsión" "46. Así mismo participaron en el debate la Iglesia, la Organización Internacional de Trabajadores (OIT) y la oposición.

En junio de 1966, Solís anunció que se estaba llevando a cabo un estudio previo para una futura Ley Sindical en el que todos aquellos que tuviesen cualquier nivel de representatividad podrían participar ${ }^{47}$. Este llamamiento coincidió con la celebración de las elecciones sindicales, en las que Solís había venido impulsando la participación de los trabajadores con una intensa campaña propagandística bajo el lema "Vota al mejor". Lo que favoreció una alta participación, que según la OSE alcanzó un $83,3 \%$ de los posibles votantes.

Antes de elaborar la Ley se tuvo que proceder a la modificación por la LOE del Fuero del Trabajo. Ello supuso la desaparición de los conceptos establecidos en los primeros momentos del "Nuevo Estado" de "unidad, totalidad y jerarquía", la supresión de la afirmación de que

45 López Rodó, L.: Memorias. El principio del fin, III, Barcelona, Plaza \& Janes / Cambio 16, 1992, pág. 262.

46 Romero, E.: Tragicomedia..., op. cit., pág. 166.

47 "Declaraciones de José Solís", Solidaridad Nacional, 6 de junio de 1966. 
el Sindicato era un instrumento al servicio del Estado y la condición de que sólo los militantes de Falange podian ostentar la jerarquía sindical, requisito este último que ya se venía incumpliendo. Se llevó a cabo una desvinculación expresa del Sindicato respecto al Estado ${ }^{48}$, se incluyó la negociación colectiva del trabajo con rango de Ley Fundamental ${ }^{49}$, se procedió a un robustecimiento de la configuración comunitaria de la empresa ${ }^{50}$ y se remitió a leyes ordinarias la regulación de los conflictos colectivos de trabajo, que dejaron de ser ilegales por sí mismos ${ }^{51}$.

Dichas modificaciones hacian necesaria la anunciada ley, por lo que la OSE realizó una consulta-informe en la que «intervinieron más de 168.000 productores", con el objeto de establecer los criterios en los que se debería de asentar la nueva legislación, los cuales serian sometidos al pleno del Congreso Sindical (IV Congreso Sindical, celebrado en Tarragona en mayo de 1968). El objetivo del mismo era realizar un anteproyecto que sería elevado al Gobierno y a la vez desplazar dentro del propio Sindicato a los sectores inmovilistas ${ }^{52}$.

Todo este proceso estuvo controlado por los jerarcas sindicales, así como el propio Congreso Sindical cuya representatividad fue puesta en "tela de juicio» por los miembros del Gobierno. De hecho López Rodó denunció que de los 582 participantes con derecho a voto "tan sólo 193 habian sido elegidos por el Consejo Nacional de Trabajadores. Entre los restantes, 190 fueron libremente designados por el Ministro Delegado Nacional de Sindicatos y 199, elegidos por el Consejo Nacional de Empresarios" ${ }^{53}$. También fue cuestionado el procedimiento de discusión, sirva de ejemplo la descripción del mismo sobre un punto de la ponencia:

«El presidente del Congreso y delegado nacional de Sindicatos se levanta: "Aprobamos este punto". Un rumor corre por la sala, "Aprobado", ratifica el señor Solís. Se oyen en el fondo de la sala voces de "No, no". "Está bien

48 Declaración xI, punto $5^{\circ}$; Declaración XIII, que fue sustituida en gran parte.

49 Declaración III, punto $4^{\circ}$.

50 Declaración III, punto $4^{\circ}$, final, y Declaración vill, punto $3^{\circ}$.

51 Declaración $\mathrm{XI}$, punto $2^{\circ}$.

52 Dentro dei Sindicato existian dfiversas corrientes, pero la labor de Solis, junto a la de Arturo Espinosa Poveda y Antonio Chozas Bermudez, entre otros hicieron posible la renovación iniciada con la llegada del primero al poder. Se trataba, en palabra de los mismos, de un proceso de renovación que buscaba llegar a "una concepción democrática de la evolución institucional", en Iglesias Seglas, C.: Comentario..., op. cit., pág. 70.

53 López Rodó, L.: Memorias..., 11, op. cit., pág. 502. 
- vuelve a tomar la palabra el presidente-, aprobado con algunos votos en contra". Se pasa al tema siguiente» ${ }^{54}$.

El texto aprobado por el Congreso Sindical fue remitido al Gobierno para que fuese convertido en proyecto de ley. $Y$ pese a las declaraciones de Solís sobre su inmediata remisión a las Cortes, ésta se demoró hasta el 13 de septiembre de 1969, es decir un año y cinco meses, debido a una intensa polémica sobre el mismo que llevó al propio ministro a declararlo "secreto oficial» durante el mes de septiembre de 1969; lo cual muestra las fuertes discrepancias que existian en un gabinete agotado.

Las voces en contra del proyecto iban desde el propio Franco, que confesó a Carrero el 23 de enero de 1969 que desde "1937 ando patinando con los Sindicatos" ${ }^{55}$; hasta de miembros del Gobierno como López Rodó que afirmó:

«De prosperar ese proyecto - le dije (se dirige a Franco)- sólo podria gobernar en España quien tuviera en sus manos la Organización Sindical: es el único grupo, en las Cortes, en el Consejo Nacional y en el Consejo del Reino, que obedece a una disciplina política" ${ }^{56}$.

En el mismo sentido se manifiesta Carrero Blanco al comunicar contundente y reiteradamente a Franco:

«... la conveniencia del cese de Solis por empecinarse en sacar adelante una Ley Sindical tan recusable como los proyectos de Leyes Fundamentales de 1956, pues otorgaba todo el poder a la Organización Sindical, a semejanza de Arrese que pretendia todo el poder para la Secretaria General del Movimiento".

"La Organización Sindical, o más exactamente los altos cargos de la misma, todo ellos de libre designación, pretenden de hecho el asalto del poder. Mientras la ponencia discute y se debate prácticamente ante un muro infranqueable, la prensa del Movimiento y la prensa Sindical, que, lógicamente, deben ser totalmente obedientes al Ministro Secretario General que es de quien dependen por la duplicidad de sus cargos, están constantemente azuzando al Gobierno a que envie a las Cortes la Ley por ellos propuesta. No hay día en que no haya una o varias reuniones sindicales, en las que no surja la conminación, cada vez más insolente, al Gobierno para que remita la Ley a Cortes" ${ }^{57}$.

\footnotetext{
54 Figueruelo, A., Mundo, 1 de junio de 1968. Citado por Garcia-Nieto, J.N., A. Busouets y S. MARIMON: La nueva ley sindical, Barcelona, 1970, pág. 34

5.5 LOPEZ RODO, L.: Memorias..., II, op. cit., pág. 385.

5.6 lbid, pág. 387.

5) Ibid, pags. 402 y 423. La segunda de las citas se encuentra contenida en un Memorándum de Carrero Blanco a Franco titulado: Consideraciones sobre la situación politica, con fecha 7 de mayo de 1969. (El subrayado es nuestro).
} 
Este clima de crisis de gobierno se verá confirmado en octubre de 1969 con la salida de Solís y la derrota de su proyecto político. A esta derrota colabora también la Iglesia que en un documento del Episcopado ${ }^{58}$ se reafirma en posturas ya mantenidas anteriormente, insistiendo en la necesidad de una mayor autonomía de los sindicatos, así como en una mayor representatividad de los mismos, y, por último, haciendo hincapié en que se promuevan los «medios eficaces" para solucionar "los posibles conflictos». Dicho tono no era nuevo, pues algunos sectores de la Iglesia habían venido manteniendo desde los años cincuenta ${ }^{59}$ una actitud crítica frente al Sindicato. En unas declaraciones de Monseñor Cantero (procurador en Cortes), se ponen en evidencia estas diferencias:

"Su articulado (se refiere al proyecto de Ley) no me satisface en aspectos tan sustanciales como los referentes a la representatividad y autonomía sin. dicales (y) abrigo la esperanza de que (...), se ajuste más al contenido y al espiritu del magisterio de la Iglesia y de la Organización Internacional del Trabajo en materia sindical» ${ }^{60}$.

A estas críticas se sumó la OIT que aunque no se posicionó directamente sobre el proyecto de ley, sí lo hizo indirectamente. La OIT se mostró preocupada por el estado de excepción y los malos tratos a los sindicalistas. Creía conveniente una "amnistía o indulto" para los que se encontraban detenidos y procesados, pero advertía que dicha medida «no resolvería definitivamente el problema mientras continúen sujetas a la legislación penal actividades que, según los principios de la OIT, constituyen actividades sindicales genuinas" ${ }^{61}$. Respecto a los Congresos Sindicales denunció la preponderancia en los mismos de la línea política, lo cual les restaba representatividad. En este sentido la crítica era similar a la que se realizaba desde ciertos sectores del Gobierno, e incluía diversas "condiciones" que sería conveniente que la nueva Ley Sindical cumpliese:

5. Declaración del Espiscopado español sobre los principios de la doctrina social de la lglesia que deben informar el "futuro sindicalismo". 25 de julio 1968.

${ }_{53}$ En 1955 el obispo de Las Palmas, Monseñor Pildain, en unas declaraciones se preguntaba si el sistema sindical vigente era acorde o no con la doctrina de la lglesia, llegando, a la conclusión de que no. En una línea más critica existen diferentes documentos de grupos dependientes de la Iglesia, como la Declaración de los Consiliarios de Vanguardias Obreras, Madrid, 9 de enero 1969, Fondo Maria Luisa Suàrez (AHCO-FPM), carpeta 67-15

60 Declaraciones a El Noticiero de Zaragoza, en octubre de 1969, reproducidos por el Boletín Oficial del Arzobispado, año cvili, 11, noviembre 1969, págs. 717 y ss.

6: Punto 1.141 del «Informe OlT», España Perspectiva, 1970, Madrid, Guadiana Publicaciones, 1970, pág. 319. 
«En primer lugar, todos los cargos investidos de autoridad en el Movimiento sindical, incluído el de más alto nivel, deberían ser llenados por elección.

..., convendría que la Ley asegurase la autonomía completa y la igualdad efectiva en la práctica de las asociaciones de trabajadores y las asociaciones de empresarios; ...

..., convendría que la Ley asegurase que todos los funcionarios designados por la Organización Sindical estén sujetos a la autoridad de los dirigentes elegidos y reciban sus instrucciones de ello;...

..., convendría que la Ley estableciese que la Organización Sindicał, si bien sometida a las leyes del Estado, no esté sujeta a dirección o control de ningún movimiento político, ...

.... la Ley deberia garantizar una libertad de expresión y de reunión..." 62 .

También hubo críticas dentro del propio Sindicato, tal fue el caso del Consejo Provincial de Trabajadores de Navarra. Desde la oposición sindical ${ }^{63}$ se planteó así mismo una alternativa completa al modelo existente. $E$ incluso en los Jurados de Empresa, los vocales obreros pusieron de manifiesto su apoyo al informe de la OIT ${ }^{64}$ y la necesidad de establecer «Sindicatos verdaderamente representativos».

La crisis de octubre de 1969, en la que jugó como detonante el «escándalo de MATESA» ${ }^{65}$, supuso la derrota política del grupo de Solís y su salida del Gobierno, siendo sustituido en la Secretaria General del Movimiento por Torcuato Fernández Miranda, y creándose un ministerio sin cartera para la Organización Sindical que fue ocupado por Enrique García del Ramal, hombre que no compartía la línea política, ni tenía el mismo poder que Solis. Podemos decir que a partir de entonces se inicia la

62 Punto 1.244, en lbid, págs. 342 y 343

63 Véase entre otros el Proyecto que las Comisiones Obreras proponen a los trabajadores ante la nueva Ley Sindical, mayo, 1967; y los Acuerdos tomados en la junta de presidentes y vicepresidentes del ramo del metal de la comarca del Bajo Llobregat ante el proyecto de Ley Sindical presentada a las Cortes y principios básicos, que somete esta junta a todos los trabajadores de la comarca en pro de un auténtico sindicalismo obrero, Cornellá, 14 de octubre de 1969.

64 «Asunto oficio de fecha 27-6-69 dirigido al Presidente de la Sección Social del Sindicato Provincial del Metal requiriendo se nos envie copia íntegra de lo tratado en Ginebra en la reunión celebrada por la O.I.T., y sobre los acuerdos adoptados en Tarragona por el Consejo Nacional de Trabajadores", en Actas del Jurado de Empresa de Perkins, no 199, 21 de octubre 1969, Madrid, (AHCO-FPM), carpeta $3 / 24$, pág. 7.

65 El "escándalo" apareció en la prensa controlada por Manuel Fraga y José Solís, a principios de agosto de 1969. Mientras que un sector del Gobierno (Garcia Moncó, Espinosa San Martín, López Bravo, López Rodó...) era partidario de echar tierra al asunto; otro sector, entre los que estaban naturalmente Solis y Fraga, era partidario de eluz y taquígrafos", en VILA REYES, J.: El atropello..., op. cit., págs. 70-73. 
decadencia de la propia OSE, por lo que ya, y esto es lo sobresaliente, no importará que cuente con la nueva ley, pues ha disminuido su papel entre los diversos grupos que participan en el Gobierno. Esta crisis nos da una idea de la propia naturaleza del régimen, en el cual no es definitivo el contenido de las leyes, sino el poder político que se encuentra detrás de las mismas. Todo el debate anterior entre los grupos representados por Solís y López Rodó no se justifica en sí mismo por un determinado proyecto legislativo, sino por "espacios de poder" que determinan la capacidad última de decisión sobre el conjunto de la política, por lo que la discusión legislativa se convierte en un medio de confrontación y descalificación del contrincante, y no en un fin.

Aunque la aprobación del proyecto de ley no estaba en peligro, y más tras la caída de Solis, la OSE puso en marcha todo su aparato propagandístico para "legitimar su posición de preeminencia, autojustificar la labor de sus dirigentes en la "modernización" sindical contenida en la ley, y tratar de influir con todo ello" ${ }^{66}$ en la opinión pública. Desde Madrid se dirigió un operativo ${ }^{67}$ pidiendo a cada Sindicato Provincial un informe semanal de los actos de propaganda que en apoyo del proyecto de ley se habían realizado. Estas actuaciones se complementaron con la actividad de los periódicos del Movimiento, que las apoyaron sin reserva.

En el debate de las Cortes sobre el proyecto de Ley Sindical se presentaron seis enmiendas a la totalidad ${ }^{68}$, ninguna de ellas de procuradores sindicales que, en cambio, participaron activamente en los debates (hubo un total de 1.138 enmiendas); aunque ya no podían subsanar con «su ley: la derrota política sufrida con el cambio de Gobierno. A éste no le importaba ya el texto de la misma, por lo que las diferencias entre el proyecto y la ley no significaron «un cambio fundamental a los anteriores proyectos» ${ }^{69}$, siendo considerada por la oposición democrática como «una gran ocasión perdida» 70 .

6e Martin de la Guardia, R.: "La Organización Sindical Española ante la Ley de febrero de 1971: tacticas propagandisticas en la conformación de un estado de opinión", Investigaciones Históricas, x1, Valladolid, 1991, pág. 282. Este trabajo pone en evidencia para el caso de Valladolid el importante esfuerzo propagandistico realizado por la OSE, es de figurar que se llevó a cabo en las demás provincias.

67 Orden del Director de la Oficina Central de Delegaciones Provinciales de Sindicatos, de 17 de octubre de 1970 .

68 Cinco realizadas por procuradores del tercio familiar y ta sexta por un representante de colegios, cámaras y asociaciones.

gg CABAllero, J.J.: "Clase obrera y relaciones de trabajo", en Manuel Fraga, et. at. (Comps.): La España de los años setenta, 1, Madrid, Moneda y Crédito, 1974, pág. 678. Consultar también GIL Rozles, J.M": "Ley Sindical: principios básicos y iegulación efectiva", Cuadernos para el Diálogo, febrero 1971, págs. 21-27.

70 Ludevio, M.: Cuarenta años de Sindicato Vertical, Barcelona, Laia, 1976, pág. 50. 
La ley fue aprobada definitivamente por el Pleno de las Cortes del 16 de febrero de $1971^{71}$ y valorada por el nuevo ministro de Sindicatos como un paso adelante en la línea de perfeccionamiento del régimen "sin que se halla producido la menor solución de continuidad; es más, convirtiendo en realidad aspiraciones vivamente sentidas como aquellas que se contenían ya en la primitiva redacción del Fuero del Trabajo..." ${ }^{72}$. Desde un punto de vista legal los cambios introducidos por esta ley "no afectaron a la permanencia de las notas de unidad, obligatoriedad y carácter jurídico-público de los sindicatos" ${ }^{73}$ y la OSE, al quedar asimilada como un Ministerio "descafeinado" y con escaso poder político, se integró plenamente en los proyectos gubernamentales del momento.

Cambiaron poco los Sindicatos, seguían estableciendo un régimen de autocracia sindical, lejos de potenciar la representatividad de la que tanto hablaban. En realidad no se movieron de «su lugar» ${ }^{74}$; pero, en cambio, perdieron parte del poder que habian tenido en especial durante la década anterior.

Buena muestra de la pérdida de representatividad del Sindicato ante los patrones, y por consecuencia la disfuncionalidad del mismo a la hora de regular las relaciones laborales, fue la decisión de estos últimos de negociar directamente con Comisiones Obreras ${ }^{75}$. La negociación, al margen del Sindicato, se hizo de forma especial en los temas referidos a salarios y a jornadas de trabajo ${ }^{76}$. De igual forma actuaron las empresas multinacionales ${ }^{77}$.

71 El día 29 de marzo de 1971, Raúl Morodo y Leopoldo Torres presentaron sendos escritos en los que solicitaban de la Comisión Permanente de las Cortes Españolas la iniciación de procedimiento de Recurso de Contrafuero contra la Ley Sindical, y que a través del consejo del Reino se propusiera al Jefe del Estado la suspensión de la ley durante la tramitación del recurso. Ambos escritos insistian en una versión democrática de la ley, tratando de potenciar la linea representativa. La Comisión Permanente de las Cortes el día 31 de marzo de 1971 acordó trasladar las peticiones al Consejo Nacional, el cual rechazó ambos escritos.

72 Garcia-Ramal, E.: Discurso pronunciado ante las Comisiones Permanentes de los Consejos Nacionales de Trabajadores y de Empresarios, (17 de octubre de 1972). Madrid, Servicio de Información y Publicaciones Sindicales, 1972, pág. 14.

73 Montora Melgar, A.: Derecho del Trabajo, Madrid, Tecnos, 1988, pág. 122.

74 Martínez Cuadrado, M.: Anuario Político Español 1970, Madrid, Cuadernos para el Diálogo, 1971, pág. 697.

75 "En la celebración de un acto sobre La problemática económica de Catalunya a la que asistió López Ródo [...], Pere Durán Farell, directivo entonces de La Maquinista Terrestre y Maritima, declaró que para evitar más dificultades se habian visto obligado a entablar conversacıones con Comisiones Obreras, dejando de lado el Sindicato Oficial", Doblón, 3-9 de julio 1976.

76 PRIES, L.: "Cualificación, relaciones laborales y mercado de trabajo: el concepto de la "estrechez" del ámbito empresarial en España", Revista Española de Investigaciones Sociológicas, 41, 1988, págs. 81-114.

77 Redero, M.: «Las relaciones laborales en el franquismo y la transición democrática (19581978) 
La decadencia continuó hasta que se planteó la "reforma sindical», en la que Rodolfo Martín Villa -ministro de Relaciones Sindicales del primer Gobierno de la Monarquía- hizo un esfuerzo importante por mantener una sola central sindical ${ }^{78}$. El fracaso del proyecto de Martín Villa llevó a Suárez a la desaparición progresiva de la OSE, primero con la creación de la Administración Institucional de Servicios Socio-Profesionales (AISS) ${ }^{79}$ y, posteriormente, poniendo fin a la sindicación obligatoria unos días antes de las primeras elecciones democráticas ${ }^{80}$.

\section{LA OPOSICIÓN ANTE EL SINDICATO VERTICAL}

Uno de los rasgos que más ha llamado la atención dentro de la evolución de la oposición al franquismo y de los que más ha incomodado al propio régimen ha sido la paulatina entrada de militantes de la oposición dentro de los cargos representativos del Sindicato. Con ello no se establecía un proceso de integración, sino de confrontación desde la legalidad.

Como proceso de integración ${ }^{81}$ podríamos considerar los contactos mantenidos entre la dirección del Sindicato y un grupo de "cenetistas" con el fin de llevar a cabo "una importante negociación" ${ }^{82}$. La misma se produjo a mediados de los años sesenta, si bien es verdad que en los años anteriores se habían incorporado, más a título individual que colectivo, antiguos miembros de dicho sindicato a la OSE, y se habían llevado a cabo contactos a tal fin, como los habidos en 1947.

El objetivo de Solís era ampliar la base de representación sindical y mejorar su posición política, aunque lo presentara ante el Gobierno como unas «negociaciones» que trataban «de dividir al adversario y de incorporarle a la Organización Sindical uno a uno y por los cauces abiertos" ${ }^{83}$. Para el sector de la CNT que propició las conversaciones se trataba de salir del aislamiento, división y marginalidad en la que se encontraba dicha

78. Véase MINISTERIO DE TRABAJO/INSTITUTO DE RELACIONES LABORALES Y DE SE. GURIDAD SOCIAL: La reforma sindical en España durante el primer gobierno del Rey (Noviembre 1975-Junio 1976), Madrid, Informe de Documentación Social Española, 1, 1976.

79 Real Decreto-Ley 19/1976, 8 de octubre.

so Real Decreto-Ley 31/1977, 2 de junio. (BOE, 8 de junio).

81 BULNES, R.: "Del sindicalismo de represión al sindicalismo de integración", Morizonte español 1966, II, Paris, Ruedo lbérico, págs. 285-325.

82 Romero, E.: Tragicomedia..., op. cti., pág. 95. Según este autor, por parte de la CNT: "La cabeza principal era Lorenzo Ínigo y estaba acompnado por Enrique Marco, Eduardo de Guzmán, Orobón Fernández, Francisco Rollán, Gregorio Gallego y Manuel Fernández".

83 LOPEZ Rodó, L.: Memorias..., 11, op. cit., pág. 35. 
organización ${ }^{84}$. Se creó una "comisión de expertos» en la que se llegó a los siguientes acuerdos:

«... el logro de la unidad obrera; la independencia respecto al Estado o a los Gobiernos; diferenciación respecto a las organizaciones empresariales, y autonomía plena en cuanto a las organizaciones políticas actuales y a las que pudieran aparecer en el futuro" ${ }^{85}$.

Los acuerdos no fueron aceptados principalmente por Camilo Alonso Vega - Ministro de Gobernación-y Carrero Blanco, confirmando dicha postura el propio Franco, el cual nunca confió en esas conversaciones por lo que forzó a Solís a acabar con las mismas.

De mayor interés es el proceso de confrontación que se produjo con la oposición, la cual decidió utilizar los cargos de representatividad sindical como forma de acción política. A ello se refirió el propio Franco:

"Esta importancia que la Organización Nacional de Sindicatos ha alcanzado en la vida pública y su participación en el progreso pacífico de la nación, explica el que se haya convertido en el blanco preferido de los opositores políticos y agentes de la anti-España; tratando de parasitarla infiltrando agentes en su seno» ${ }^{86}$.

Antes de entrar en el tema es conveniente dejar claro que dicha táctica supuso una fractura dentro de la oposición, que va a tener consecuencias en la posterior transición sindical.

La Unión General de Trabajadores (UGT) estimaba, tras analizar la naturaleza de los Sindicatos en la que coincidía la mayor parte de la oposición, que la participación en los mismos constituía una «trampa» ${ }^{87}$, una “táctica oportunista" ${ }^{88}$, que implicaba reforzar y dotar de credibilidad a un "organismo antiobrero" como la «CNS-OSE».

Ahora bien, tras estas rotundas declaraciones, se ocultaba una realidad mucho más compleja dentro de UGT. Así, mientras se mantenía la negativa

${ }_{34}$ Véase en este sentido, Ramos, C.: "El Cincopuníismo en la CNT", 1965-1966. (Investigación sobre el proceso de discusión mantenida entre un grupo de militantes libertarios y representantes del Sindicato Vertical. Abril 1965-abril 1966)", en J. TUSELL, et. al.: La oposición al Régimen de Franco, T. I, vol. 2, Madrid, UNED, 1990, págs. 137-155.

as Romero, E.: Tragicomedia... op. cit., págt. 96.

86 "Acto afirmación sindical», Barcelona, 4 de julio de 1966.

87 "Participación o entrentamiento": UGT, 349, junio, 1974, pág. 1.

is Redondo, N.: Apertura del xxx Congreso de la UGT, Madrid, 15 de abril de 1976. 
a «infiltrarse» en la OSE, se reconocía que algunos miembros de UGT venían participando "dentro de los sindicatos verticales" ${ }^{89}$.

El debate sobre el tema va a ocupar una parte importante de la discusión interna de los afiliados de la UGT. En él se refleja de forma reiterada el miedo a ser absorbidos por los comunistas, los cuales mantenían abiertamente una postura favorable a la participación en las elecciones sindicales. En todo caso se combinó una línea estratégica "inmovilista" con una actividad sindical más pragmática, a lo cual colaboró el cambio en la composición interna de la clase obrera y la presión de la realidad ${ }^{90}$. En las zonas más conflictivas la participación se hacia conveniente, tal y como sucede en Vizcaya ${ }^{91}$. En todo caso, es necesario señalar que UGT llevó a cabo en el interior del país una actividad sindical realmente débil ${ }^{92}$.

En una táctica opuesta se van a situar los comunistas, ciertos sectores socialistas - vinculados a Unión Sindical Obrera (USO) y al Partido Socialista del Interior - y las organizaciones obreras cristianas ${ }^{93}$. Fueron los comunistas quienes se plantearon con más claridad y decisión la posibilidad de participar en los "sindicatos verticales". En 1941, Vicente Uribe desde México daba la instrucción al partido en el interior para actuar dentro de la OSE ${ }^{94}$. En un documento interno del PCE remitido a Franco por la policía se afirma que:

"(...) es conveniente utilizar los Sindicatos para plantear las reivindicaciones de los trabajadores, utilizando formas y métodos distintos, un

89 CENTRE D'ESTUDIS HISTORICS INTERNACIONALS (CEHI). DOC. Sindical. UGT. "Proposición táctica", Mariano Cubillo, s.l. (1953?). Citado por MATEOS, A.: "Comunistas, socialistas y sindicalistas ante las elecciones del "Sindicato Vertical", 1944-1967", Espacio, Tiempo y Forma, 1. UNED, Madrid, 1987, págs. 379-411. También del mismo autor: "Sindicalismo socialista y movimiento obrero durante la dictadura franquista (1939-1976)", en S. Juliá (Coord.): El socialismo en España, 1, Madrid, Pablo Iglesias, 1986, págs. 317-348; y más recientemente: El PSOE contra Franco, Madrid, Pablo Iglesias, 1993.

90 "Teniamos problemas serios dentro de la organización, porque te llegaba la consigna de que no participaras con los comunistas, pero no tenias más remedio. O rompias la disciplina de la organizació o te unias a las acciones", en Guindal, M. y R. Serrano: La otra transición. Nicolás Redondo: El sindicalismo socialista, Madrid, Unión Editorial, 1986, pág. 45.

91 IBARRa Guell, P.: El movimiento obrero en Vizcaya: 1967-1977, Bilbao, Universidad del Pais Vasco, 1987, págs. 220 y 221.

92 ReDero, M. y T. Pérez: "Sindicalismo y transición folítica en Españâ", Ayer, 15, 1994, pág. 195.

93 Véase en este sentido: Domingez, J.: Organizaciones obreras cristianas en la oposición al franquismo (1951-1975), Bilbao, Mensajero, 1985; y DiAZ-SALAZAR, R.: "Los cristianos, la lucha por la democracia y la creación del nuevo movimiento obrero (1947-1977)", xx Siglo, 16, págs. 5-14.

94 Véase TCHACH, C.: "Crisis y reorganización del socialismo español", en TCACH, C. y C. REYES: Clandestinidad y Exilio. Reorganización del sindicato socialista, 1939-01953, Madrid, Pablo Iglesias - Fundación Largo Caballero, 1986, págs. 91-95; y LóPEZ RAIMUNDO, G.: Primera clandestinidad. Memorias, Barcelona, Antártida/Empúries, 1993, pág. 198. 
lenguaje diferente en consonancia con las posibilidades que estos ofrecen, utilizando a los trabajadores menos conscientes y más atrasados, para que sean ellos los que intervengan en forma más activa en su seno" ${ }^{95}$.

Dicha táctica se combinó con la lucha armada durante los años cuarenta, siendo ésta última abandonada debido a su esterilidad y al alto coste tanto humano como organizativo, así como a su inoperancia política.Durante 1956 se va a producir un cambio significativo en la línea política del PCE ${ }^{96}$, abriéndose una revisión táctica que se conocerá bajo el lema de la «reconciliación nacional», la cual supondrá una línea divisoria con la anterior etapa. En el plano de la política obrera se mantendrá durante cierto tiempo la cada vez más mortecina Oposición Sindical Obrera (OSO), al mismo tiempo que se verá con entusiasmo creciente el nacimiento de "Comisiones Obreras", que aparecen y desaparecen en función de conflictos puntuales.

No conduce a nada la polémica sobre la fecha del nacimiento de Comisiones Obreras (CCOO) ${ }^{97}$, ya que parece claro que éstas, con un carácter espontáneo, vinieron existiendo desde los años cincuenta, e incluso antes. Lo que sí tiene interés es cuándo se decide dotar a dicha forma de organización de un carácter estable, combinando tanto la espontaneidad del movimiento con la necesidad de estructurarlo. En este sentido influyó decisivamente el cambio en la estructura de la oposición y en las formas de protesta, así como la existencia de una organización estable, como el PCE, que permitió dotar a CCOO de la infraestructura necesaria ante la represión y los vaivenes de la conflictividad. Sirva de ejemplo concreto lo ocurrido en el sector del metal a principios de los años sesenta en Madrid: Allí no desapareció la "comisión obrera" cuando el problema que había originado su creación se solventó, sino que siguió funcionando "primero en el propio sindicato vertical, y luego fuera de él» ${ }^{98}$. A partir de dicho momento el nuevo «movimiento-organización» se va dotando de una dirección estable y de textos programáticos, en los que, junto a una crítica global al sistema capitalista y la reafirmación de la necesidad de construir una central sindical única e independiente, se realiza un llamamiento a todos los militantes obreros para:

\footnotetext{
95 "Noticias sobre actividades del PCE", con fecha 14 de junio de 1941, en Documentos Inéditos para la Historia del Generalisimo Franco, T. 11-2, documento num. 174, Madrid, Azor, 1992, pág. 170.

45. MORAN, G.: Miseria y grandeza del Partido Comunista de España 1939-1985, Barcelona, Plantea, 1986, págs. 253-304.

${ }_{37}$ Véase Ruiz, D. (Dir.): Historia de Comisiones Obreras (1958-1988), Madrid, Siglo XXI, 1993.

yy Camacho, M.: Confieso que he luchado. Memorias, Madrid, Tema de Hoy, 1990, pág. 171.
} 
"9.- b) Colaborar en todos los intentos de constitución de comisiones de enlaces y jurados, así como de militantes obreros, en los diversos sectores de trabajo, y abierta a todos, para luchar en forma unitaria por las reivindicaciones inmediatas de derechos y la maduración del Movimiento Obrero. Las Comisiones Obreras, creadas por los propios trabajadores, son un movimiento indispensable, sin subordinación a ninguna tendencia ideológica."

La aparición de CCOO causó preocupación dentro del Gobierno y en la OSE. Tanto Romero Gorría, como Solis se entrevistaron con Marcelino Camacho a principios de 1965 con objeto de frenar el incremento de la conflictividad y, en el segundo de los casos, también con la intención de integrarlos. Es evidente que ambas propuestas fracasaron y ante el auge de CCOO se decidió utilizar "lo de siempre»: la represión. Asi una sentencia del Tribunal Supremo (16 de febrero de 1967) las declara ilegales, vinculándolas al PCE, iniciándose con ello una amplia operación policial contra los dirigentes y militantes de CCOO que, aunque con los lógicos altibajos, se mantuvo al menos hasta la muerte de Franco.

Un claro ejemplo de la represión citada es el «proceso $1.001 »$, que se originó por la detención el 24 de junio de 1972 de diez dirigentes de CCOO "en una residencia aneja al convento de los padres oblatos de Pozuelo de Alarcón - Madrid-» y dio lugar a la posterior condena de diez encausados por el Tribunal de Orden Público a penas muy duras: A Marcelino Camacho y Eduardo Saborido se les impuso una condena de veinte años de reclusión menor, y a Nicolás Sartorius de diecinueve años ${ }^{100}$. En torno a dicho proceso se montó una importante campaña de solidaridad, que si bien se vio truncada por el asesinato del presidente del Gobierno el mismo día del inicio del juicio, no impidió que numerosos sectores de la oposición democrática apoyaran a los encausados. No olvidemos que el abogado defensor de Camacho fue Joaquín Ruiz-Giménez, ex-ministro de Educación.

Junto a esta represión sobre los dirigentes, la más constante y dura fue la realizada sobre los enlaces sindicales elegidos democráticamente por sus compañeros de trabajo. Es difícil hacerse una idea cuantitativa de dicha represión. En todo caso la cifra de 127 enlaces represaliados que aporta la propia OSE es muy inferior a la real ${ }^{101}$, ya que las fuentes no oficiales hablan de “más de un millar» 102.

1000 "El T.O.P. condena a 162 años de cárcel a diez trabajadores", Gaceta de Derecho Social, 31, diciembre 1973, págs. 12 y 13. (En adelante GDS).

101 La OSE afirma que entre septiembre de 1966 y marzo de 1968 tan sólo hubo 127 enlaces represaliados, en Informe del Secretario General al IV Congreso Sindical de la OSE, Tarragona, mayo 1968, pág. 12.

102 Almenoros, F., et. al.: El sindicalismo de clase en España (1939-1977). Barcelona, Peninsula, 1978, pág. 48. 
Entre octubre de 1971 y diciembre de 1972 fueron dados de baja por "extinción de contratos» más de diecisiete mil enlaces, renunciaron más de seiscientos y fueron desposeídos veinticinco ${ }^{103}$. Estos datos, aunque no son importantes si tomamos el conjunto de enlaces elegidos, sí muestran «que las desposesiones han afectado esencialmente a los representantes sindicales de las empresas más importantes en número de trabajadores y en combatividad" 104.

Las formas de represión utilizadas por las empresas contra los enlaces sindicales fueron muy variadas. La detención por la policia y el posterior despido por inasistencia al trabajo fue una táctica habitual ${ }^{105}$. Existen otros casos como el denunciado por una enlace sindical que tras ser elegida se le cambió de puesto de trabajo por la dirección de la empresa, lo cual representó pérdida de salario y no tener contacto con los compañeros que la habían votado ${ }^{106}$. El traslado fue una de las tácticas más utilizadas, incluso antes de ser elegido como le ocurrió a un trabajador de Telefónica ${ }^{107}$. También se practicó el trato vejatorio a los enlaces:

«..., tan pronto se me ordena que esté de mozo de camión como dice que coja la escoba y tengo que barrer esto. Como es natural lo hacen con el único fin de que los trabajadores piensen que si esto lo hacen con un representante sindical donde le ampara un régimen jurídico que garantiza el cumplimiento de sus funciones y ejercicio de su actividad representativa ¿Qué les ocurrirá a ellos?»108.

Pero va a ser la suspensión de funciones y el posterior despido la fórmula preferida. Así ocurrió con Marcelino Camacho, al que en primer lugar se le rebajó de categoría laboral ${ }^{109}$ y posteriormente se le suspendió de

103 BASCO, J.M.: “23.000 enlaces cesados», GDS, 22, marzo 1973, pág. 15.

104 Martín, E. y J. Salvador: Los enlaces sindicales, Madrid, Laia, 1976, pág. 201.

105 La falta al trabajo de dieciocho enlaces sindicales de la Empresa Nacional Bazán, que se encontraban detenidos, fue considerada "causa justa" de despido por la Magistratura de Trabajo, Garcia VALDÉS, C.: "La Bazán": despidos y listas negras", GDS, 15, agosto 1975, pág. 5.

106 «Expediente de denuncia a la Delegación de Trabajo sobre derechos sindicales de una trabajadora contra la empresa Barbudo, s.a. (sector Químicas)", Fondo de María Luisa Suárez, (AHCO-FPM), 27 de mayo 1972, carpeta, 19-28.

107 «Expediente de infracción de la ley de elecciones sindicales por coacciones de un trabajador contra la empresa Compañia Telefónica Nacional de España (Sector Comunicaciones", Fondo Maria Luisa Suárez. (AHCO-FPM), 15 de junio 1975, carpeta, 16-7.

${ }_{108}$ «Expediente de denuncia a la Delegación de Trabajo sobre categoría profesional y derechos sindicales de un trabajador contra la empresa Unvisa, s.a. (sector Vidrio), Fondo María Luisa Suárez. (AHCO-FPM), 18 de abril 1973, carpeta, 23-24.

109 Véanse las Actas del Jurado de Empresa números 122 (20 de abril 1966) y 125 (12 de mayo 1966), Actas del Jurado de Empresa de Perkins", (AHCO-FPM), carpetas, 2/30 y 2/33. 
funciones ${ }^{110}$; situación que se repitió con otros miembros del Jurado de Empresa, como Julián Ariza, hasta variar por completo la fisonomía del Jurado. De hecho desde enero de $1967^{111}$, los empresarios tuvieron las manos libres para despedir a los "obreros díscolos", pese a la existencia de unas supuestas garantías de dichos representantes.

Estas actuaciones, que no eran la excepción sino la norma, denunciar una "equivocada estrategía», fueron utilizadas como argumentos por aquellos que estaban en contra de participar en las elecciones sindicales. Pero no fue así, ya que el efecto más importante de dichas represalias, pese a los costos personales que supusieron, fue el contrario al que las autoridades perseguian - aunque en ocasiones no de forma inmediata, como ocurre con las elecciones de 1970- y buena muestra de ello fue la creciente participación en las elecciones sindicales, asi como los beneficios obtenidos por los trabajadores al contar con "compañeros" que realmente los defendían y representaban.

\section{LAS ELECCIONES SINDICALES: EL TRIUNFO DEL ENTRISMO}

La participación en las elecciones sindicales de trabajadores contrarios a los planteamientos de la OSE se produjo desde los primeros momentos. Tanto en 1944 como en 1947 se utilizó esta vía por «el carácter utilitario (...) que podian ofrecer dichas estructuras" ${ }^{112}$, hecho que se confirmó en las elecciones de 1950 sobre todo en Cataluña ${ }^{113}$, y que sirvió para impulsar las acciones reivindicativas que se desarrollaron en dicha región entre 1951 y 1953.

El cambio que supuso la Ley de Convenios Colectivos Sindicales y el auge de la conflictividad impulsaron la participación en las elecciones que, como ya hemos visto, también fue favorecida por el propio Sindicato. El punto de inflexión se produce en las decisivas elecciones de 1966, en las que se experimentó una mayor participación, así como un reforzamiento de CCOO, que obtuvo unos buenos resultados electorales: "muchos representantes de $\mathrm{CCOO}$ que presentaron su candidatura abiertamente $y$

110 "Acta 133", Actas del.., op. cit., 24 de agosto 1966, carpeta 2/41, pág. 1.

111 Sentencia del Tribunal Supremo de 23 de enero de 1967, de conformidad con los artículos del 208 al 213 del Procedimiento laboral, se posibilitaba a los empresarios la no admisión de los enlaces sindicales a cambio del pago de una indemnización.

:12 Sartorius, N.: El resurgir del movimiento obrero, Barcelona, Laia, 1975, pág. 25.

113 LUdEvid, M.: El movimiento obrero en Cataluña bajo el franquismo, Barcelona, Avance 1977, pág. 11. 
con plataformas reivindicativas bien elaboradas, llegaron a tener en parte mayorias aplastantes en las grandes empresas de los cinturones industriales" ${ }^{114}$. Este último aspecto, no deseado por los jerarcas sindicales, condujo a la intensificación de la represión, lo cual, unido a la congelación de la negociación colectiva, supuso un reflujo del movimiento obrero, que comenzará a recuperarse a finales de 1969.

Las elecciones sindicales de 1971 estuvieron especialmente marcadas por el debate en torno a la conveniencia o no de participar en las mismas. Ello provocó una caída en la participación, sobre todo en ciertas zonas donde el "boicot" fue la norma. Asi, en empresas tan importantes de la provincia de Vizcaya como Euskalduna, Naval, Westinghouse o Firestone la participación apenas superó el $20 \%$, aunque en otras fue mayor. En Cataluña la participación fue importante, pero no llegó al porcentaje de las anteriores elecciones; el triunfo de las candidaturas «obreras» fue «notable» ${ }^{115}$, pese a que sólo fueron renovados la mitad de los cargos sindicales, algunos de los cuales fueron posteriormente represaliados:

"Los candidatos obreros obtienen 8 de los 18 puestos del Jurado. Los líderes encarcelados sacan votaciones plebiscitarias. (...) A los pocos días, en la huelga del turno de noche, la SEAT despide a casi todos los miembros representativos del Jurado. Desde ese momento el Jurado se convierte en un claro enemigo de la organización obrera en SEAT, la cual tiene que prescindir del cauce sindical para impulsar las reivindicaciones" ${ }^{116}$.

En Madrid las elecciones de 1971 supusieron también un descenso en la participación, ya que dentro de CCOO algunos sectores, como la ORT o la extrema izquierda, defendieron el «boicot». A pesar de ello, la dirección de CCOO, monopolizada por el PCE, las valoró como «un importante paso adelante» ${ }^{117}$. En todo caso estas dudas y debates en el movimiento sindical supusieron una radicalización de los conflictos, que se hará notar durante los últimos años de la vida del dictador.

Un cambio a favor de la plena participación, en una situación marcada por la "crisis" en la que se encontraba el propio régimen, se observa en la convocatoria de 1975. En ellas CCOO hizo un esfuerzo por «ganar las

114 KOHLER, H.D.: El movimiento sindical en España, Madrid, Fundamentos, 1995, págs. 85 y 86.

115 RIERA, I. y J. BOtella: El Baix Llobregat. 15 años de luchas obreras, Barcelona, Blume, 1976, págs. 79 y 80

116 Miguelez, F.: SEAT la empresa modelo del Régimen, Barcelona, Dopesa, 1977, pág. 232.

11 Casas, J.I. et al.: Getafe. Lucha obrera bajo el franquismo, Madrid, Unión Sindical de Madrid de Comisiones Obreras, 1977, pág. 61. 
Elecciones en todos los centros de trabajo" ${ }^{118}$, presentando junto a demandas laborales un programa en el que se incluia la petición del derecho de reunión y huelga, la libertad sindical, la readmisión de los despedidos y la amnistía. En esta ocasión no se produjo la división de 1971, pues la USO, que en algún momento había tenido dudas, en estas elecciones llamo a la "ocupación de los cargos sindicales". La participación según la OSE superó el $88 \%$.

En todas las fuentes consultadas existe unanimidad a la hora de apostar por el triunfo de las Candidaturas Unitarias y Democráticas (CUDs). Las variaciones van a darse respecto al volumen de las mismas, pues el Servicio de Información de la Organización Sindical trató de minimizarlas; ${ }^{119}$ no obstante, los resultados conocidos desmienten tal afirmación.

En la región valenciana triunfaron en la primera vuelta "las CUDs en todas las grandes y medianas empresas del metal, madera, banca, vidrio y cerámica, transporte, piel y calzado, hospitales, textil, químicas, artes gráficas..." ${ }^{120}$. En el País Vasco la cifra de participación superó el $80 \%$ y en la inmensa mayoría de ellas triunfaron las candidaturas de "oposición" y unitarias, pese a la ruptura existente en el seno de CCOO, y a la implantación en esta región de UGT y ELA-STV, ambas partidarias, siguiendo su tradición, del "boicot» ${ }^{121}$. El mismo éxito se repitió en Barcelona y en Madrid, sobre todo en las grandes empresas, tal es el caso en el primero de dichos lugares de SEAT, Roca, Siemens, Olivettio Gallina Blanca donde las CUDs obtuvieron más del $78 \%$ de los votos emitidos. En Madrid ocurrió igual en empresas como Credit Lyonnais, Televisión, ENASA, Kelvinator, CASA, o Marconi ${ }^{122}$. En resumen, se puede hablar de "una victoria rotunda de las candidaturas unitarias y democráticas ${ }^{123} \%$.

Aunque existen algunos ejemplos en las anteriores elecciones, la infiltración en el segundo nivel de representación sindical había venido siendo excepcional, no sólo por las dificultades del sistema electoral, sino también por el incremento de diversas formas de represión para impedirlo (desposesión de cargos, traslados, despidos, cambio de categoría,...). En todo

\footnotetext{
118 Declaración de la Coordinadora General de Comisiones Obreras, abril 1975.

119 CUE, G.: "Las elecciones sindicales de 1975 en la historia del sindicalismo español de posguerra", Revista de Estudios Sindicales, 41, pág. 38.

120 Beneyto, P. Y J. Pico: Los Sindicatos en el Pais Valenciano (1975-1981), Valencia, Insitució Alfons el Magnánim, 1982, pág. 15.

121 IBARRA, P.: El movimiento..., op. cit., pág. 397

i22 GDS, anexo al núm. 48-49, mayo-junio 1975, págs, 123 y 124.

123 Diaz CARdiel, V. et. al.: Madrid en huelga: enero 1976, Madrid, Ayuso, 1976, pág. 70
} 
caso los resultados de 1975 en este nivel fueron también positivos para la oposición:

«De acuerdo con la Organización Sindical, sólo el 14 por 100 de los presidentes de agrupación fueron reelegidos, por lo que la renovación alcanzaria al 86 por 100. Los porcentajes de puestos obtenidos por las candidaturas democráticas van de 60 al 100 por 100 en los sectores más importantes: Metro: 8 de 12; Electricidad: 29 de 29; Editoriales: 30 de 30; Hospitales: 19 de 21, y; Telefónica: 7 de 14» 24 .

Se puede afirmar a manera de conclusión que desde el interior del Sindicato se producen intentos de cambio por parte de ciertos grupos de la clase politica del franquismo, con el fin de dotarlo de una mayor representatividad, pero dichos intentos se vieron "torpedeados" desde otros sectores franquistas ante el temor de que cualquier cambio pudiera socavar la función "original» del Sindicato o dar más poder a un determinado grupo. No obstante, no se puede ocultar que el Sindicato incrementó sus "cuotas de poder" gracias a la Ley de Convenios Colectivos y a la actuación de José Solís que lo utilizó como punta de lanza para presionar a favor de sus proyectos políticos. Pero como hemos indicado, desde su destitución el Sindicato adquiere cada vez más la fisonomía de un «monstruo" burocrático, que comienza a convertirse en una incomodidad debido a la constante infiltración de representantes de la oposición.

El "entrismo" contribuyó a reforzar la oposición y sirvió para que los activistas tuviesen foros legales desde los cuales llegar a los trabajadores y poder mejorar sus condiciones de trabajo y de vida. También ayudó a la formación de nuevos líderes sindicales, y permitió la utilización de los locales de la OSE para la celebración de asambleas y reuniones de los trabajadores. Por último, sirvió para que los jurados de empresa fueran los receptores de las demandas obreras y los impulsores de las protestas 125. Es evidente que tuvo costos, pero no se puede dudar de los importantes beneficios que dicha táctica representó desde una perspectiva histórica. Nicolás Redondo reconoce que dicha participación supuso un precio para sus mentores, pero también afirma que la UGT pagó su continuo «boicot»" 126 .

124 CUE, G.: “Las elecciones...”, op. cit., pág. 41.

125 FISMAN, R.: Working Class Organization and Political Change: The Labor Moverment and the Transition to Democracy in Spain, Diss., Yale University, 1985, págs. 202 y ss.

126 Guindal, M. y R. Sertrano: La otra transición..., op. cit., pág. 44. 